\title{
Effect of Maternal Oral Hydration Therapy on Maternal and Perinatal Outcome in Isolated Oligohydramnios
}

\author{
${ }^{1}$ Rajani Rawat, ${ }^{2}$ Ruchika Garg, ${ }^{3}$ Amit Kaushik, ${ }^{4}$ Ravi Sachan
}

\begin{abstract}
Objective: To evaluate the effect of maternal oral hydration therapy in 3rd trimester pregnancies with isolated oligohydramnios on amniotic fluid index (AFI) and maternal and perinatal outcome.

Materials and methods: A prospective study was conducted on 100 pregnant women in 3rd trimester with isolated oligohydramnios. Women were advised to drink 2 liters of fluids orally over 1 hour per day in the form of water, fruit juices, coconut water and to take rest in left lateral position. Amniotic fluid index was re-evaluated by ultrasonography done at 24 hours and then repeated at 48 hours of oral hydration therapy. Difference in prehydration and posthydration AFI was calculated for each selected cases at different intervals. Women were asked to continue the therapy of 2 liters per day orally in addition to routine fluid intake till delivery. All the women were followed till delivery and maternal and perinatal outcome was analyzed.
\end{abstract}

Results: The mean AFI increased from $6.23 \pm 1.06 \mathrm{~cm}$ (pretreatment) to $7.47 \pm 0.58 \mathrm{~cm}$ at 24 hours $(p<0.001)$ and to $7.80 \pm$ $1.47 \mathrm{~cm}$ at 48 hours of oral hydration therapy ( $p<0.001)$. In women with low AFI, there was increased rate of operative delivery and low Apgar score at birth. There were no perinatal deaths.

Conclusion: Maternal oral hydration therapy is simple to perform, noninvasive, nonexpensive, east to accept and an effective way of increasing AFI and results in improvement of perinatal outcome and decrease in operative interferences.

Keywords: Amniotic fluid index, Maternal oral hydration, Oligohydramnios.

How to cite this article: Rawat R, Garg R, Kaushik A, Sachan R. Effect of Maternal Oral Hydration Therapy on Maternal and

\footnotetext{
${ }^{1-4}$ Assistant Professor

${ }^{1}$ Department of Obstetrics and Gynecology, UP Rural Institute of Medical Science and Research, Saifai, Uttar Pradesh, India

${ }^{2}$ Department of Obstetrics and Gynecology, SN Medical College, Agra, Uttar Pradesh, India

${ }^{3}$ Department of Social and Preventive Medicine, UP Rural Institute of Medical Science and Research, Saifai, Uttar Pradesh, India

${ }^{4}$ Department of Pediatrics, UP Rural Institute of Medical Science and Research, Saifai, Uttar Pradesh, India

Corresponding Author: Rajani Rawat, Assistant Professor Department of Obstetrics and Gynecology, UP Rural Institute of Medical Science and Research, Saifai, Uttar Pradesh, India Phone: 9457678964, e-mail: rajanirawat21@gmail.com
}

Perinatal Outcome in Isolated Oligohydramnios. J South Asian Feder Obst Gynae 2015;7(2):64-67.

Source of support: Nil

Conflict of interest: None

Date of received: 12 May

Date of acceptance: 22 June

Date of publication: August 2015

\section{INTRODUCTION}

Oligohydramnios is one of the prevalent threatening condition to fetal health. It is a harbinger of adverse perinatal outcome, commonly associated with intra-uterine growth restriction, impairment of fetal pulmonary development, pressure induced deformities, congenital malformations, fetal distress, increased operative delivery and meconium aspiration.

Maternal hydration therapy has been suggested in the literature to restore amniotic fluid volume to its normal range, and thereby reduce the associated perinatal morbidity and mortality. The present study was conducted to assess the efficacy of maternal oral hydration therapy especially on amniotic fluid index (AFI) in diagnosed cases of isolated oligohydramnios in 3rd trimester and its impact on perinatal outcome.

\section{MATERIALS AND METHODS}

The study was conducted in the department of obstetrics and gynecology, UP Rural Institute of Medical Science and Research, Saifai, Uttar Pradesh, India, over a period of 2 years. This prospective study was done to assess the effect of maternal oral hydration on AFI and pregnancy outcome in these women. Oligohydramnios was defined as AFI less than ' 10 ' and severe oligohydramnios as AFI less than ' 5 ' measured by four quadrant technique on ultrasonography. Amniotic fluid index was obtained sonographically by dividing the maternal abdomen into four quadrants, the linea nigra was used to divide abdomen into right and left halves and umbilicus was used to separate upper and lower halves. The largest amniotic fluid pocket was identified in each quadrant free of fetal limbs and cord loops and its vertical diameter was taken. All four vertical diameters were added to obtain AFI in centimeters. $^{1}$ 
All pregnant women in 3rd trimester of pregnancy attending antenatal OPD and indoor were recruited for the study. Inclusion criteria were: women with singleton pregnancy with well established dates at 28 to 42 weeks of gestational age, with intact membranes, without any medical disorders with no congenital fetal anomalies, who were diagnosed as isolated oligohydramnios clinically and confirmed on ultrasonography through AFI of less than $10 \mathrm{~cm}$, were included in the study. Women with structural fetal malformation, maternal diseases as cardiac disease, pre-eclampsia, eclampsia, renal impairment, severe anemia, diabetes, thyroid disorders, multiple pregnancy, nonreactive nonstress test (NST), intrauterine fetal death, premature and prelabor rupture of membranes were excluded from the study.

The selected cases were subjected to detailed history, general, systemic and obstetrical examination. Antenatal investigations were done especially to rule out systemic medical disorders. Written informed consent was taken from each selected case after thoroughly explaining about oral hydration therapy. Pre-treatment ultrasonography was done to note the AFI. Women were advised to drink 2 liters of fluids orally over 1 hour per day in the form of water, fruit juices, coconut water and to take rest in left lateral position. Amniotic fluid index was re-evaluated by ultrasonography done at 24 hours and then repeated at 48 hours of oral hydration therapy. Difference in prehydration and post-hydration AFI was calculated for each selected cases at different intervals. Women were asked to continue the therapy of 2 liters per day orally in addition to routine fluid intake till delivery. All the women were followed till delivery and perinatal outcome was analyzed. Mode of delivery and neonatal outcome in the form of Apgar score were recorded. Results were subjected to statistical analysis.

Table 1: Demographic profile of patients

\begin{tabular}{llll}
\hline \multirow{2}{*}{ Parameters } & Classes & \multicolumn{2}{l}{ No. of cases } \\
$(n=100)$ & Percentage \\
\hline Age & $<20$ years & 5 & 5 \\
& 20-30 years & 68 & 68 \\
Parity & $>30$ years & 27 & 27 \\
& G1 & 37 & 37 \\
& G2 & 26 & 26 \\
Socioeconomic & G3 & 19 & 19 \\
status & G4 & 18 & 18 \\
& Low & 31 & 31 \\
Gestational age & Middle & 51 & 51 \\
& High & 18 & 18 \\
& $28-32$ weeks & 29 & 29 \\
& $32-36$ weeks & 38 & 38 \\
& $36-40$ weeks & 24 & 24 \\
& $>40$ weeks & 9 & 9 \\
\hline
\end{tabular}

\section{OBSERVATIONS}

Total 100 women with 3rd trimester isolated oligohydramnios were included in the study over the defined period of 2 years.

The mean age of the women was 27.2 years and majority (51\%) belonged to middle socioeconomic status (Table 1). Oligohydramnios was found to be more common in primigravida (37\%). Most of the women selected for the study belonged to 36 to 40 weeks gestational age (38\%).

Severe oligohydramnios, i.e. AFI $<5$ was found in $11 \%$ cases and maximum number of women $(35 \%)$ had pretreatment AFI between 5 and 6 (Table 2). After 24 hours of oral hydration therapy, none of the women were having severe oligohydramnios (i.e. AFI < 5) and majority $(34 \%)$ had AFI between 7 and 8. Mean prehydration AFI was $6.23 \pm 1.06 \mathrm{~cm}$ while the mean posthydration AFI at 24 hours was $7.47 \pm 0.58 \mathrm{~cm}$. After further continuation of oral hydration therapy, the amniotic fluid volume increased and at 48 hours the mean AFI was $7.80 \pm 1.47 \mathrm{~cm}$.

Out of 100 women of isolated oligohydramnios, vaginal delivery occurred in $52 \%$ cases while $12 \%$ required assisted instrumental vaginal delivery (Table 3 ). Elective cesarean section was performed in $20 \%$ cases while $28 \%$ women underwent emergency cesarean section. In women with AFI $<7,25 / 32$ (78.12\%) required cesarean section while $23 / 78(29.48 \%)$ required cesarean section in women with AFI $>7$ and this was found to be statistically significant $(\mathrm{p}=0.0002)$.

Maximum number of neonates in low AFI group had Apgar score $<7$ (Table 4). There was no intrapartum deaths in our study but seven neonates expired within the first 8 days of birth, out of which six neonates belonged to severe oligohydramnios group. Common intrapartum complications that neonate suffered were meconium aspiration and birth asphyxia and later few developed hypoxic ischemic encephalopathy and hyaline membrane disease.

Table 2: Amniotic fluid index before and after oral hydration therapy

\begin{tabular}{llll}
\hline $\begin{array}{l}\text { Amniotic fluid } \\
\text { index }\end{array}$ & $\begin{array}{l}\text { Pretreatment } \\
\text { (O hour) cases }\end{array}$ & $\begin{array}{l}\text { '24 hours' of } \\
\text { oral hydration } \\
\text { cases }\end{array}$ & $\begin{array}{l}\text { '48 hours' of } \\
\text { oral hydration } \\
\text { cases }\end{array}$ \\
\hline $4-5$ & 11 & - & - \\
$5-6$ & 35 & 12 & 8 \\
$6-7$ & 30 & 22 & 24 \\
$7-8$ & 18 & 34 & 30 \\
$8-9$ & 6 & 21 & 19 \\
$9-10$ & - & 11 & 10 \\
$10-12$ & Not included & - & 9 \\
Mean \pm SD & $6.23 \pm 1.06$ & $7.47 \pm 0.58$ & $7.80 \pm 1.47$ \\
t-test value & & $10.21^{*}$ & $8.61^{\#}$ \\
p-value & & $<0.001^{*}$ & $<0.001^{\#}$ \\
\hline
\end{tabular}

${ }^{*} 0$ hour vs 24 hours; ${ }^{\#} 0$ hour vs 48 hours 
Table 3: Association between AFI and mode of delivery

\begin{tabular}{|c|c|c|c|c|c|}
\hline $\begin{array}{l}\text { Parameters } \\
(N=100)\end{array}$ & $A F I$ & $\begin{array}{l}A F I \\
5-6.9 \\
(N=32)\end{array}$ & $\begin{array}{l}A F I \\
7-8.9 \\
(N=49)\end{array}$ & $\begin{array}{l}A F I \\
>9 \\
(N=19)\end{array}$ & $\begin{array}{l}\text { Test of } \\
\text { significance }\end{array}$ \\
\hline \multirow[t]{6}{*}{ Mode of delivery } & Vaginal delivery $(\mathrm{N}=52)$ & 7 & 33 & 12 & \multirow{6}{*}{$\begin{array}{l}\chi^{2}=17.20 \\
d f=2 \\
p=0.0002\end{array}$} \\
\hline & • Normal vaginal & 5 & 27 & 8 & \\
\hline & - Instrumental & 2 & 6 & 4 & \\
\hline & $\operatorname{LSCS}(\mathrm{N}=48)$ & 25 & 16 & 7 & \\
\hline & - Elective CS & 9 & 7 & 4 & \\
\hline & - Emergency CS & 16 & 9 & 3 & \\
\hline
\end{tabular}

Table 4: Perinatal outcome based on post-treatment AFI

\begin{tabular}{|c|c|c|c|c|}
\hline $\begin{array}{l}\text { Parameters } \\
(N=100)\end{array}$ & $A F I$ & $\begin{array}{l}A F I \\
5-6.9 \\
(N=32)\end{array}$ & $\begin{array}{l}A F I \\
7-8.9 \\
(N=49)\end{array}$ & $\begin{array}{l}A F I \\
>9 \\
(N=19) \\
\end{array}$ \\
\hline \multirow[t]{2}{*}{ Low Apgar score at birth } & $<7(70)$ & 31 & 39 & Nil \\
\hline & $>7(30)$ & 1 & 10 & 19 \\
\hline \multirow[t]{2}{*}{ Perinatal deaths } & Intrapartum deaths & 0 & 0 & 0 \\
\hline & Early neonatal deaths & 6 & 1 & 0 \\
\hline
\end{tabular}

\section{DISCUSSION}

Oligohydramnios is the decreased amount of amniotic fluid volume around the fetus in amniotic cavity. It is more common in 3rd trimester and incidence increases if pregnancy continues beyond term because of placental aging. Oligohydramnios accompanies broad range of disorders and anomalies of fetus (multicystic kidneys, renal agenesis, urinary tract obstruction), maternal medical disorders affecting the placental bed (anemia, IUGR, pre-eclampsia, viral infections, diabetes insipidus, dehydration) and prerupture of membranes leading to leakage of amniotic fluid. 'Isolated oligohydramnios' describes low amniotic fluid volume, without any maternal or fetal disorder. We selected the cases of isolated oligohydramnios for evaluating the effect of oral hydration therapy on AFI and neonatal outcome.

In our study, isolated oligohydramnios was more common in primigravida (37\%). Garmel et $\mathrm{al}^{2}$ found $67 \%$ while Jandial et $\mathrm{al}^{3}$ found $60 \%$ of the women to be nulliparous with isolated oligohydramnios.

Amniotic fluid volume depends upon gestational age, it is maximum at 36 weeks and then progressively decreases. Therefore, we selected the 3 rd trimester cases and most of the isolated oligohydramnios (33\%) belonged to 36 to 40 weeks gestational age group. Oligohydramnios has invariably been associated with adverse perinatal outcome, such as fetal distress (ante/intrapartum fetal heart rate decelerations and meconium passage, cord compression), induction of labor, operative delivery and poor Apgar score at birth. Multiple therapeutic options are suggested for oligohydramnios as serial transabdominal or trans-cervical amnio-infusion, intravenous hydration, Desmopressin (Ddavp) and amniotic sealing techniques in rupture of membranes cases but all are invasive, costly and have their own disadvantages. Oral maternal hydration therapy is simple, safe, noninvasive and easy for treating oligohydramnios without any complications.

Ghafarnejad $^{4}$ reported that with maternal oral hydration therapy, mean AFI improved from 50.8 to $67.2 \mathrm{~mm}$ ( $\mathrm{p}<0.001$ ) while it increase $3 \mathrm{~d}$ from $62.3 \mathrm{~mm}$ to $74.7 \mathrm{~mm}$ in 24 hours in our study.

Literature suggests that oral hydration increases the AFI in both oligohydramnios and normal pregnancy by $2.01 \mathrm{~cm} \mathrm{(95 \%} \mathrm{Cl;} \mathrm{1.43-2.56)} \mathrm{and} 4.5 \mathrm{~cm}(95 \% \mathrm{Cl} ; 2.9-6.1)$ respectively. ${ }^{5,6}$ Fait et $\mathrm{al}^{7}$ reported similar results and pointed that short-term improvement in amniotic fluid volume persists into long-term, when maternal hydration is continued by drinking ' 2 ' liters/day fluid for a week which is confirmed in present study when mean AFI increased upto $7.80 \pm 1.47 \mathrm{~cm}$ after 48 hours. Improvement in AFI in isolated oligohydramnios depends on the gestational age at the time of oral hydration and the time available till delivery.

In our study, $48 \%$ cases underwent cesarean section. This high cesarean rate in our study is because of lack of available time for hydration, lack of intrapartum continuous and internal monitoring facility and presence of other obstetrical factors. Bangal et $\mathrm{al}^{8}$ reported $44 \%$ while Jandial et $\mathrm{al}^{3}$ reported $56 \%$ cesarean section rate in their study.

Table 3 clearly demonstrates that cases in which AFI improved to 7 and above after oral hydration had higher vaginal delivery rate and better Apgar score at birth. Similar results were seen by Golan et $\mathrm{al}^{9}$ and Charu et al. ${ }^{3}$ There was no intrapartum deaths in our study but $7 / 100(7 \%)$ neonates expired in NICU in the first week of life due to different perinatal complications which is 
almost comparable with $10 \%$ of Jandial et $\mathrm{al}^{3}$ and $6.4 \%$ of Casey et al. ${ }^{10}$ Bangal VB et al ${ }^{8}$ reported $8 \%$ still births and $16 \%$ neonatal deaths in their study on perinatal outcome in 100 oligohydramnios cases.

\section{CONCLUSION}

Maternal oral hydration therapy is simple, safe, noninvasive and effective method to improve the amniotic fluid volume in isolated oligohydramnios cases but requires continuous therapy for long-term to improve the neonatal outcome.

\section{REFERENCES}

1. Phelan JP, Ahn MO, Smith LCDR, Carl V. Amniotic fluid index measurements during pregnancy. J Reprod Med 1987;32: 601-604.

2. Garmel SH, Chelmow D, Sha SJ, et al. Oligohydramnios and appropriately grown fetus. AM J Perinatol 1997;14:359-363.

3. Jandial C, Gupta S, Sharma S, Gupta M. Perinatal outcome after antepartum diagnosis of oligohydramnios at or beyond 34 weeks of gestation. JK Science 2007 Oct-Dec;9(4):213-214.
4. Ghafarnejad M, Tehrani MB, Anaraki FB, Mood NI, Nasehi L. Oral hydration therapy in oligohydramnios. J Obstet Gynaecol Res 2009;35:895-900.

5. Hofmeyr GJ, Gulmezoglu AM. Maternal hydration for increasing amniotic fluid volume in oligohydramnios and normal amniotic fluid volume. Cochrane Database Sust Rev 2002;(1):CD 000134.

6. Kilpatrick SJ, Safford KL. Maternal hydration increases amniotic fluid index in women with normal amniotic fluid. Obstet Gynaecol 1993;81(1):49-52.

7. Fait G, Pauzner D, Gull I, et al. Effect of I week of oral hydration on the amniotic fluid index. J Reprod Med 2003;48(3): 187-190.

8. Bangal VB, Giri PA, Sali BM. Incidence of oligohydramnios during pregnancy and its effect on maternal and perinatal outcome. J Pharmac Biomed Sci 2011;12(12):1-5.

9. Golan A, Lin G, Evron S, et al. Oligohydramnios: maternal complications and fetal outcome in 145 cases. Gynecol Obstet Invest 1994;37:91-95.

10. Casey BM, McIntire DD, Bloom SL, et al. Pregnancy outcomes after antepartum diagnosis of oligohydramnios at or beyond 34 weeks of gestation. Am J Obstet Gynaecol 2000;182: 909-912. 